REVISTA ANDALUZA DE ANTROPOLOGÍA.

NÚMERO 3: MIGRACIONES EN LA GLOBALIZACIÓN.

SEPTIEMBRE DE 2012

ISSN 2174-6796

[pp. 247-253]

http://dx.doi.org/10.12795/RAA.2012.i03.14

\title{
FERRÁNDIZ, FRANCISCO (2011) Etnografías contemporáneas. Anclajes, métodos y claves para el futuro. Madrid: Anthropos Editorial, 271 pp.
}

\author{
Ángel del Río Sánchez \\ Universidad Pablo de Olavide
}

Existe una amplia bibliografía concebida como manuales de investigación que desentraña el método etnográfico con destino preferente hacia estudiantes universitarios. El libro que presentamos: Etnografías contemporáneas. Anclajes, métodos y claves para el futuro, aunque pensado, según palabras de su autor, Francisco Ferrándiz, para personas que se inician en el intrincado mundo de la antropología social y cultural a través de su método más idiosincrásico: el trabajo de campo, pretende superar tal finalidad para erigirse en un texto que contribuya al debate y la reflexión sobre las dificultades metodológicas de nuestra disciplina. Si bien, la estructura de contenidos es muy similar a la de muchos manuales al uso: marcos teóricos, historia de la etnografía, el trabajo de campo y todas sus técnicas anexas, etc., Ferrándiz lo aborda de un modo original y sugerente mixturando para la reflexión global, su propia experiencia investigadora con las aportaciones teóricometodológicas extraídas de una amplísima bibliografía, mayoritariamente en inglés.

El libro podríamos considerarlo como una contribución novedosa al dilatado debate sobre el método etnográfico que ha sido consustancial al propio desarrollo de la teoría 
antropológica. Aunque es a partir la década de 1970, cuando irrumpe con insistencia en el ámbito de las ciencias sociales las preguntas sobre cómo se representa la realidad social, cuando el debate adquiere un nuevo sentido, poniendo en primera línea del quehacer antropológico a la etnografía en sustitución de los grandes paradigmas teóricos. La irrupción en las universidades estadounidenses y la paulatina extensión y consolidación por todo el orbe antropológico de la llamada antropología interpretativa, alimentó una concepción de la etnografía como narrativa y del etnógrafo como autor que sigue vigente y que está en los fundamentos de este ensayo.

El libro de Ferrándiz contiene una reflexión sobre su propia experiencia investigadora por lo que podría calificarse, en parte, como unas "memorias de campo" en la línea de autores como Paul Rabinow y su Reflexiones sobre un trabajo de campo en Marruecos o Nigel Barley y su El antropólogo inocente, por citar algunos títulos de mayor impacto incluso fuera del ámbito de la disciplina. Aunque cabe matizar que, a diferencia de estas obras $-\mathrm{y}$ sus autores-, que han recibido duras críticas desde ciertas posiciones cientifistas que consideran sus trabajos como un subgénero dentro de la antropología, el ensayo de Ferrándiz no se reduce a una "introspección narcisista" o un "ingenioso anecdotario" tal como fueron catalogados los anteriores. La propia experiencia investigadora se concibe como fuente esencial de recursos que solo se utiliza, ocasionalmente, para ilustrar algunos debates y cuestionar los límites de algunas técnicas de investigación. Y siempre en relación con las experiencias y reflexiones de otros autores que ha considerado de interés para una propuesta global de debate en torno a las problemáticas metodológicas que pueden preocupar hoy día en el seno de la antropología.

Las referencias a su trabajo de campo - que constituyen buena parte de su labor investigadora como profesional-, corresponden, una primera, tratada con mayor profundidad, a una investigación sobre el culto de posesión espiritista de María Lionza en Venezuela realizada los primeros años de la década de 1990 (Ferrándiz, 2004); y otra, tratada de manera más tangencial, y que ocupa su interés investigador desde 2003, sobre las exhumaciones de las fosas comunes de la guerra civil y la represión franquista producidas en España en esta última década, y de las que tiene numerosas publicaciones, algunas de las cuales pueden consultarse en la página Web del proyecto del CSIC que coordina Las políticas de la memoria.

El libro se divide en cinco capítulos que podemos agrupar en tres grandes bloques para su comentario. En el primero (capítulos 1, 2 y 3), de contenido histórico y conceptual sobre la etnografía y los métodos teóricos que la sustentan, el autor muestra sus preferencias y las influencias que han posibilitado su formación antropológica que le lleva a optar por determinados caminos epistemológicos y metodológicos. En el segundo (capítulo 4) disecciona con una envidiable pormenorización el proceso etnográfico con sus diversas técnicas de investigación, situando a la persona que se adentra en el trabajo de campo en 
estado permanente de perplejidad ante lo que denomina el laberinto de la investigación etnográfica. Y en el tercero se aproxima a los nuevos escenarios de la etnografía derivados del proceso de globalización, analizando algunos campos relacionados con la violencia y el sufrimiento social.

Ferrándiz posee una sólida formación de la Universidad de California en Berkeley en la que defendió su tesis doctoral sobre el culto espiritista en Venezuela. Las influencias berkeleyanas, que no esconde, de antropólogas y antropólogos como Ahiwa Ong, Nancy Scheper-Hughes y Paul Rabinow, con el compromiso social, los perennes dilemas éticos en la labor investigadora, la reformulación de las relaciones entre trabajo de campo y teoría, la reflexividad crítica, entre otros muchos aspectos (Fernández de Rota, 2012), forman parte de su bagaje intelectual y sus preocupaciones antropológicas que son abordadas con detalle a lo largo del libro. Así como también es evidente el influjo de ciertas teorizaciones sobre la etnografía de autores como Geertz, Clifford, Marcus, entre otros, considerados como adalides de las corrientes posmodernistas y que produjo en el pasado aceradas polémicas con los situados en torno a posiciones cientifistas o positivistas (Llobera, 1990, Clifford y Marcus, 1991 y Fernández de Rota, 2012). Hay que señalar, no obstante, que Ferrándiz, tal como señala en el capítulo 2 en un esquemático, pero necesario, análisis sobre los métodos científico y hermenéutico en la antropología, no contempla una oposición incompatible entre los grandes paradigmas. Alejándose de todo dogmatismo y de criterios rígidos opta por un pluralismo teórico-metodológico que integre los elementos que puedan ser útiles de ambas propuestas para el conocimiento antropológico, lo que no debe entenderse como una falta de coherencia. Con esta idea el autor disecciona el concepto de etnografía siguiendo las aportaciones de una diversidad de autores, relevantes y dispares, como Velasco y Díaz Rada, Pujadas, Marcus y Fischer, entre otros, para llegar a definirlo como una práctica ecléctica y reflexiva, donde el principal instrumento de investigación es el investigador mismo, y las formas de practicar la antropología pueden ser múltiples, y deben adaptarse a un cúmulo de circunstancias históricas y socioculturales en permanente dinamismo.

El segundo bloque correspondiente al capítulo 4, el más extenso, está íntegramente enfocado al proceso etnográfico. Es el de mayor enjundia y provecho para el estudiante de antropología o neófito investigador e, incluso, para el profesor de métodos y técnicas. El autor avisa que uno de sus objetivos es "transmitir a los alumnos la flexibilidad y versatilidad del proceso etnográfico en todos sus momentos, poniendo énfasis en que uno de los hechos cruciales de la investigación en antropología es mantener una actitud reflexiva permanente y una coherencia interna en el proceso." Y esa conciencia investigadora implica todos los momentos de la misma: desde el diseño de la investigación, la elección y la entrada al campo, la observación participante, la selección y relación con informantes, las conversaciones y entrevistas, el empleo de técnicas audiovisuales, la salida del campo y la redacción de la etnografía. 
Siguiendo la tradición etnográfica estadounidense de su formación, Ferrándiz plantea unos procedimientos para una investigación prolongada, de al menos doce meses, algo que, hoy día, en estas latitudes, parece una utopía al alcance de unos pocos. La adecuación a los imperativos presupuestarios derivados del Estado neoliberal en materia investigadora - con mayor hincapié para la antropología -, priorizan las investigaciones exprés, con pocos recursos y muchas veces sometidas a líneas temáticas muy perfiladas desde instancias ajenas, lo que repercute, sin duda, en la dificultad de aplicación de un diseño tan metódico como el planteado por el autor y, en definitiva, en la pretendida calidad del producto. No obstante, las enseñanzas y propuestas aportadas suponen un valioso arsenal de herramientas metodológicas de enorme utilidad práctica.

Ferrándiz remarca la necesaria elaboración de una hoja de ruta previa que contemple lo que queremos investigar, dónde, cómo, con qué fin, para después someterla a continuos ajustes una vez nos hayamos establecido en el campo donde las relaciones de alteridad se complejizan y no siempre están bajo nuestro control. La "imaginación etnográfica" se entiende como un requisito indispensable para poder pensar todo el proceso etnográfico adecuadamente con relación a los recursos disponibles, el contexto histórico, socioeconómico, político y cultural, los métodos y técnicas que se van a emplear, etc. Un buen diseño de investigación anticipa las líneas que entrelazan la teoría, los métodos y los datos que se espera obtener.

A pesar de las enormes transformaciones que ha sufrido la práctica etnográfica desde Malinowsky hasta nuestros días, el autor participa de una opinión mayoritaria que considera el trabajo de campo, si no ya como un rito iniciático para los antropólogos y antropólogas, sí como una de las fases fundamentales de la etnografía. Y aunque se apuntan las divergencias existentes en su conceptualización y los nuevos retos que impone la globalización, la presencia del investigador durante un tiempo más o menos prolongado en la unidad de observación se entiende como algo ineludible. Bajo esta consideración, las páginas del libro poco a poco nos van situando en una encrucijada donde es posible recorrer todos los caminos. Ferrándiz ofrece una amplia batería de propuestas y orientaciones metodológicas para la aproximación al objeto de estudio y a los otros entendida como relación intersubjetiva no exenta de tensiones. Y lo ilustra a partir de su propia experiencia mostrando un investigador a veces atribulado, desconcertado, temeroso, ridiculizado, instrumentalizado... pero con dispositivos suficientes para solventar la situación y reorientar la investigación de manera adecuada. No es difícil imaginar las dificultades para un antropólogo blanco y europeo, estudiante de una universidad yanqui y con ciertos recursos materiales, haciendo su trabajo de campo en barrios de Caracas caracterizados por un alto grado de violencia y marginación social. En este sentido las estrategias investigadoras adquieren una gran importancia para amortiguar el choque cultural y poder acceder de manera explícita al campo y encontrar un portero satisfactorio que ayude a dar los primeros pasos. 
La observación participante, definida, como el método central, definitorio y más auténtico de la etnografía - aunque no es el fetiche que llegó a ser-, se aborda desde distintas concepciones, algunas de las cuales valoran el grado de implicación del investigador: nula, pasiva, moderada o activa. En cualquier caso, la tensión entre el distanciamiento analítico y la existencia de algún tipo de compromiso emocional siempre está latente. Son muy interesantes todas las observaciones aportadas en torno a la empatía o rapport. Una de las tareas fundamentales es establecer unas relaciones de confianza, cooperación y reciprocidad con las personas que se está estudiando que satisfagan, al menos, a la gente involucrada en la investigación. La gestión de esa confianza, muchas veces puede verse alterada por las tensiones a las que está sometido el investigador durante el trabajo de campo, donde se producen complejas negociaciones en la cuales se cruzan expectativas e intentos de utilización recíproca. En definitiva el etnógrafo asume -o le hacen asumirun rol a veces no deseado.

El uso de las fuentes orales, a través de simples conversaciones hasta entrevistas estructuradas, y la utilización de otras técnicas como las historias de vida, es abordado con gran detalle y precisión en el texto. Apunta algunas de las problemáticas de esta técnica tan denostada por otras disciplinas y una serie de consejos prácticos de gran utilidad. Ferrándiz aporta, de igual modo, unas interesantes reflexiones sobre el estudio del cuerpo y de las formas de corporalidad, utilizando como referencia su investigación sobre el culto espiritista donde esta dimensión adquiere un valor especial. Su relación con informantes que son poseídos por espíritus, mostrando un amplio espectro de gesticulaciones, le lleva a utilizar el cuerpo como instrumento metodológico para elaborar lo que denomina historias del cuerpo o itinerarios corporales donde recoge las variaciones del cuerpo del informante en un período determinado y puesto en relación con el contexto sociocultural que le da sentido.

Uno de los apartados más sugerentes de este bloque es el dedicado a las técnicas y medios audiovisuales, cada vez más utilizados en las ciencias sociales. No cabe duda de que los medios gráficos y audiovisuales han cambiado la percepción del mundo y por lo tanto no pueden obviarse ni como material para el análisis ni como técnica etnográfica. Ferrándiz aplica su formación en Berkeley en esta materia como apoyo del trabajo de campo para documentar ceremonias, siguiendo las enseñanzas, entre otros, de autores emblemáticos en el cine etnográfico como el francés Jean Rouch. El uso del video, como recurso metodológico, abre un gran espectro de posibilidades para la interacción y la reciprocidad con los informantes de gran interés analítico.

El capítulo termina con la salida del campo y la escritura de la etnografía, donde se muestran diversas forma de abordar este último tramo. El autor plantea algunos debates existentes en torno a las retóricas de la antropología como plasmación final de todos los procedimientos o transformaciones del conocimiento etnográfico. La representación 
del otro ha generado fuertes controversias entre autores de distintas posiciones y con diversas estrategias. El abanico de opciones es amplio dependiendo de los marcos teóricometodológicos y pueden observarse tendencias subjetivistas que reivindican el punto de vista del nativo, otras son más exhibicionistas, militantes, experimentales, etc.

En un capítulo tan prolijo que no escatima posibilidades procedimentales, se echa en falta un apartado relativo al uso de los archivos y documentos como fuente etnográfica, que sabemos que forma parte de la labor investigadora del autor en su proyecto sobre las exhumaciones de las fosas de la guerra civil.

El último capítulo incursiona en los nuevos escenarios de la antropología provocados por el proceso de globalización. La etnografía ha tenido que replantearse los objetos de estudio y los métodos para adecuarse a las nuevas circunstancias. Aparecen nuevos ámbitos de interés para la investigación donde los escenarios se multiplican y los actores sociales se deslocalizan. El estudio de los movimientos de población como las emigraciones, las diásporas, el turismo, los reporteros, las multinacionales, entre otros muchos, obliga al uso de estrategias de investigación más flexibles y se extiende la etnografía multilocal o multisituada.

Uno de los temas que ha despertado un enorme interés en las últimas décadas en la disciplina, debido en gran parte al incremento de su visibilidad a través de los medios, ha sido la violencia y el sufrimiento social. Ferrándiz plantea un debate general sobre algunas características específicas de la llamada antropología de la violencia, e incursiona en algunos escenarios concretos y las formas de ejercer el rol del antropólogo con metodologías dispares para el trabajo de campo. Los dilemas éticos, que están presentes de forma transversal en toda la obra, sobre la relación con los informantes y los fines de la investigación, adquieren una dimensión especial en el tratamiento de la violencia. Su experiencia de campo en barrios de Caracas impregnados de violencia y muerte, con la puesta en escena de rituales de posesión espiritista donde predominan las prácticas de automutilación y domina el lenguaje de sangre como recurso terapéutico y marcador de prestigio, le lleva al dilema de cómo representar esa violencia descarnada. Y ahí entran los debates sobre realismo, el subjetivismo, la denuncia o la pornografía de la violencia. ¿Hasta qué punto y en qué medida todo ello puede contribuir a la estigmatización de los rituales o de los colectivos? La espectacularización de las investigaciones sobre estas temáticas y en contextos de gran violencia puede conducir si no se trata adecuadamente a la extensión de los estereotipos de primitivismo y salvajismo. Hay autores como Scmidt y Schröder que opinan, frente a las posiciones subjetivistas, "que para que la antropología de la violencia haga una contribución importante al entendimiento comparativo de la violencia en el mundo, debería enfatizar el análisis causal de los aspectos materiales e históricos de los hechos estudiados." 
Las últimas páginas del libro están dedicadas a su investigación sobre las exhumaciones y la memoria traumática de la guerra civil, que tanta dimensión mediática ha adquirido en esta última década. Son muy interesantes sus reflexiones sobre el rol que ejerce un antropólogo social en un ámbito de investigación multidisciplinar donde los profesionales de la arqueología, la antropología forense, la historia, la psicología o el periodismo tienen una función delimitada y socialmente aceptada, contrariamente a nuestra disciplina cuyos resultados son más tardíos, difusos y menos visibles. En este sentido, hay que destacar la ingente labor de Ferrándiz en este campo que, pese a las dificultades de proyección de nuestros estudios, se ha convertido en un referente intelectual dentro del amplio espectro memorialístico a la altura de profesionales de otras disciplinas más mediáticas.

En definitiva estamos antes un ensayo erudito, en ocasiones denso, pero de una virtualidad incuestionablemente práctica, cuya máxima podría concretarse en el rigor conceptual y la flexibilidad metodológica. Desde mi posición, considero que sería interesante insertar muchos de los debates conceptuales y metodológicos abordados a lo largo del libro con otras coordenadas periféricas: los paradigmas y posicionamientos que emergen desde el Sur que tratan de hacer frente a los centros de poder de la disciplina, en la línea que apuntan los antropólogos Isidoro Moreno y Susana Narotzky en sendos artículos que aparecen en el primer número de esta revista.

\section{Referencias Bibliográficas}

Clifford, J. y Marcus, G. (1991) Retóricas de la Antropología. Barcelona: Júcar Universidad.

Fernández de Rota, J. A. (2012) Una etnografía de los antropólogos en EEUU. Consecuencias de los debates posmodernos. Madrid: Akal

Ferrándiz, F. (2004) Escenarios del cuerpo. Espiritismo y sociedad en Venezuela. Bilbao: Universidad de Deusto

Llobera, J. R. (1990) La identidad de la antropología. Barcelona: Anagrama 